\title{
Conversations and Misconceptions About Chemotherapy in Arabic Tweets: Content Analysis
}

\author{
Abdulrahman Alghamdi ${ }^{1,2}$, MBBS; Khalid Abumelha ${ }^{1,2}$, MBBS; Jawad Allarakia ${ }^{1,2}$, MBBS; Ahmed Al-Shehri ${ }^{1,2,3}$, \\ MBBS, ABIM, FRCPC \\ ${ }^{1}$ College of Medicine, King Saud Bin Abdulaziz University for Health Sciences, Jeddah, Saudi Arabia \\ ${ }^{2}$ King Abdullah International Medical Research Center, Jeddah, Saudi Arabia \\ ${ }^{3}$ Department of Medical Oncology, Princess Noorah Oncology Center, Ministry of the National Guard - Health Affairs, Jeddah, Saudi Arabia
}

\section{Corresponding Author:}

Abdulrahman Alghamdi, MBBS

College of Medicine

King Saud Bin Abdulaziz University for Health Sciences

King Abdulaziz Medical City, Makkah-Jeddah Hwy

Jeddah, 22384

Saudi Arabia

Phone: 9660122245000

Email: abdurrahman.essa@gmail.com

\section{Abstract}

Background: Although chemotherapy was first introduced for the treatment of cancer more than 60 years ago, the public understanding and acceptance of chemotherapy is still debatable. To the best of our knowledge, no study has assessed the conversations and misconceptions about chemotherapy as a treatment for cancer on social media platforms among the Arabic-speaking populations.

Objective: The aim of this study was to assess the types of conversations and misconceptions that were shared on Twitter regarding chemotherapy as a treatment for cancer among the Arabic-speaking populations.

Methods: All Arabic tweets containing any of the representative set of keywords related to chemotherapy and written between May 1, 2017 and October 31, 2017 were retrieved. A manual content analysis was performed to identify the categories of the users, general themes of the tweets, and the common misconceptions about chemotherapy. A chi-square test for independence with adjusted residuals was used to assess the significant associations between the categories of the users and the themes of the tweets.

Results: A total of 402,157 tweets were retrieved, of which, we excluded 309,602 retweets and 62,651 irrelevant tweets. Therefore, 29,904 tweets were included in the final analysis. The majority of the tweets were posted by general users $(25,774 / 29,904$, $86.2 \%)$, followed by the relatives and friends of patients with cancer $(1913 / 29,904,6.4 \%)$. The tweets were classified into 9 themes; prayers and wishes for the well-being of patients undergoing chemotherapy was the most common theme (20,288/29,904, $67.8 \%$ ), followed by misconceptions about chemotherapy $(2084 / 29,904,7.0 \%)$. There was a highly significant association between the category of the users and the themes of the tweets $\left(\chi_{40}^{2}=16904.4, P<.001\right)$.

Conclusions: Our findings support those of the previous infodemiology studies that Twitter is a valuable social media platform for assessing public conversations, discussions, and misconceptions about various health-related topics. The most prevalent theme of the tweets in our sample population was supportive messages for the patients undergoing chemotherapy, thereby suggesting that Twitter could play a role as a support mechanism for such patients. The second most prevalent theme of the tweets in our study was the various misconceptions about chemotherapy. The findings of our exploratory analysis can help physicians and health care organizations tailor educational efforts in the future to address different misconceptions about chemotherapy, thereby leading to increased public acceptance of chemotherapy as a suitable mode of treatment for cancer.

(J Med Internet Res 2020;22(7):e13979) doi: 10.2196/13979

\section{KEYWORDS}

internet; chemotherapy; cancer; Twitter; social media; Arab world; misconceptions; infodemiology; infoveillance 


\section{Introduction}

Although chemotherapy linguistically refers to any type of treatment with chemicals, it is now specifically used to describe cytotoxic anticancer medications, which are used to treat hematological and solid tumors [1,2]. Chemotherapeutic agents can be used alone or in combination with surgery or radiotherapy to achieve the goal of the treatment, which varies among patients based on many factors. The goal of the treatment may be to cure the cancer completely, control the cancer, stop it from spreading, or to use these agents as a palliative means to ease the symptoms and improve the patients' quality of life [3]. However, the natural mechanism of action of these chemotherapeutic agents results in relatively a wide spectrum of side effects, which might be unpleasant to the patients.

Despite continuous improvements in chemotherapy for increasing its effectiveness in treating cancer, the public understanding and acceptance of chemotherapy is still debatable. Many misconceptions can occur, thereby causing compliance issues and other problems related to the acceptance of chemotherapy as a treatment modality [4]. Most of the previous studies that assessed the perceptions and experiences of chemotherapy were performed with selected groups of patients who were either surveyed or interviewed [5-8]. However, large-scale studies attempting to understand the public views and conversations on chemotherapy are lacking. Retrieving and analyzing the contents of various social media platforms on this matter serves as an evolving method to gather information about the perceptions, misconceptions, and experiences with chemotherapy as a treatment for cancer. One of the most popular social media platforms that has been explored is Twitter, which is a large microblog wherein users can write up to 280-character messages called tweets and share them with their followers and the public. There are almost 313 million monthly active users who write around 500 million tweets daily $[9,10]$. In March 2017 , it was estimated that the number of the monthly active Twitter users in the Arab world was around 11.1 million [11]. Moreover, the number of their tweets per month in March 2016 was estimated to be 849.1 million tweets, and $72 \%$ of them were written in Arabic [11].

Twitter can be useful for exploring public opinions on health-related matters and it may play an important role in clinical settings by providing an avenue for patients to increase their knowledge regarding their diseases and by leading to a positive impact on their medical outcomes [12-14]. For example, a study showed that the mental health of the patients was affected by social media content, as positive messages were shown to reduce anxiety in patients with breast cancer who were using Twitter [12]. Moreover, social media contents show the public impression and knowledge in addition to their emotions and stress regarding diseases and their associated factors in real time $[15,16]$.

The aim of this study was to report a content analysis of the Arabic tweets regarding chemotherapy to determine the categories of the contents and to explore the possible cases of misconceptions about chemotherapy in the Arab world. This study addresses the common areas of misconceptions on cytotoxic chemotherapies in Arabic Twitter conversations, which may help to direct the future educational efforts to address these areas of misconception.

\section{Methods}

\section{Data Collection}

This observational study was conducted on Arabic tweets about chemotherapy over a 6-month period, and the main themes to which these tweets belonged were determined. A search was conducted on every publicly available tweet in Arabic containing any of the keywords mentioned in the supplementary file (Multimedia Appendix 1). Keywords were chosen on a linguistic basis; therefore, they represented all the possible spellings and abbreviations of the word "chemotherapy" in Arabic. The Twitter Archiver add-on to Google Sheets was used to collect the data [17]. This tool searches for new public tweets every 15 minutes that include any prespecified keywords and allows users to download them on a Microsoft Excel spreadsheet. Further, this tool collects the related data of every user whose tweet has been collected such as the number of people who follow those users, whom they follow, and a brief biography that users may share about themselves on the profile page. All Arabic tweets from May 1, 2017 to October 31, 2017 that contained any of the predetermined keyword(s) were retrieved. Among these, we excluded all retweets because they might deviate from the thematic analysis as they do not necessarily imply endorsement and we excluded irrelevant tweets containing the keyword but that were used in a context other than chemotherapy as a medical intervention (eg, chemical weapon attacks in Syria).

\section{Data Analysis}

To help expand the knowledge on the tweets circulated on chemotherapy, the main questions asked to generate the coding scheme were if there were misconceptions or not about chemotherapeutic agents as cancer treatments and what other patterned meanings appeared in the data set. After a thorough study of a sample of 150 tweets, the primary author generated a preliminary list of the themes of the tweets and the categories of the users. This list was used by the rest of the authors to code the same 150-tweet sample for the themes and the categories of the users, which resulted in the modification and addition of a few themes. Thereafter, another 150 tweets were used to finally test the comprehensiveness of the themes and the categories of the users along with assessing the inter-rater reliability of the coders of the main data set (JA and KA) by using the Cohen kappa coefficient. The Cohen kappa coefficients were estimated as 0.90 and 0.92 for themes and categories of users, respectively. Table 1 describes the themes of the tweets and the illustrative quotes translated from Arabic. Table 2 describes the different categories of the users who were identified on the basis of the information provided in their biographies mentioned in their Twitter profile page or on the basis of their tweets.

Using the coding scheme, 2 of the investigators (JA and KA) independently assigned each tweet and the user who shared it to the proper mutually exclusive theme and user category. Cases of ambiguity were resolved by consensus among the authors. 
Tweets under the misconception theme were further analyzed groups of users. to establish the most common misconceptions among the studied

Table 1. Descriptions of the different themes of the tweets on chemotherapy and the illustrative tweets.

\begin{tabular}{|c|c|c|}
\hline Theme of the tweet & Description & Examples of the translated tweets \\
\hline Advice and information & $\begin{array}{l}\text { Disseminating true information and advice about } \\
\text { chemotherapy }\end{array}$ & $\begin{array}{l}\text {..We use chemotherapy because its efficacy is proven-that is } \\
\text { why it is called as evidence-based medicine. }\end{array}$ \\
\hline Experience & $\begin{array}{l}\text { Sharing an experience of chemotherapy either by the } \\
\text { patients themselves or by the people who surround } \\
\text { them }\end{array}$ & $\begin{array}{l}\text {...My brother is on chemotherapy-the first session was on his } \\
\text { birthday. It was like a birthday present-a painful and sad } \\
\text { present. }\end{array}$ \\
\hline Misconception & $\begin{array}{l}\text { Sharing a false concept or a false idea about } \\
\text { chemotherapy }\end{array}$ & $\begin{array}{l}\text {... a long time ago I heard that a cure for cancer was discovered, } \\
\text { but the person who discovered it was killed because companies } \\
\text { wanted to benefit from the profits that are generated from selling } \\
\text { chemotherapeutic drugs. }\end{array}$ \\
\hline Prayers and wishes & $\begin{array}{l}\text { Saying a prayer or a wish for recovery for people re- } \\
\text { ceiving chemotherapy }\end{array}$ & $\begin{array}{l}\text {...They have been worn out by cancer, by chemotherapy...oh } \\
\text { Allah heal our patients and all Muslim patients. }\end{array}$ \\
\hline $\begin{array}{l}\text { Seeking medical informa- } \\
\text { tion/advice }\end{array}$ & Asking for medical information about chemotherapy & $\begin{array}{l}\text {...If a patient has started chemotherapy for treating cancer, } \\
\text { does he lose only the scalp hair or does he lose the hair all over } \\
\text { his body? }\end{array}$ \\
\hline $\begin{array}{l}\text { Seeking medical/financial } \\
\text { help }\end{array}$ & $\begin{array}{l}\text { Asking for medical or financial help for patients receiv- } \\
\text { ing chemotherapy }\end{array}$ & $\begin{array}{l}\text {...My mother is supposed to receive chemotherapy this week } \\
\text { but we cannot afford it. All radiographic images and reports } \\
\text { are attached. We need your help. }\end{array}$ \\
\hline $\begin{array}{l}\text { Offering medical interven- } \\
\text { tion/financial help }\end{array}$ & $\begin{array}{l}\text { Offering medical or financial help for patients needing } \\
\text { or receiving chemotherapy. }\end{array}$ & $\begin{array}{l}\text {...If anyone is in need of paclitaxel, which is a chemotherapeutic } \\
\text { drug that is well over } 3000 \text { Egyptian pounds (US \$187), please } \\
\text { do not hesitate to contact me. }\end{array}$ \\
\hline Analogy & $\begin{array}{l}\text { Using chemotherapy in an analogic way to share an } \\
\text { idea or a concept. }\end{array}$ & $\begin{array}{l}\text {..Whatever concerns you now is nothing compared to those } \\
\text { who are waiting for chemotherapy or hemodialysis tomorrow. }\end{array}$ \\
\hline Miscellaneous & Tweets that did not fit any of the other categories. & $\begin{array}{l}\text {..I hope I can discover a cancer treatment better than } \\
\text { chemotherapy. }\end{array}$ \\
\hline
\end{tabular}

Table 2. Description of the categories of the different Twitter users who tweeted on chemotherapy.

\begin{tabular}{ll}
\hline Category of the Twitter user accounts & Description of the Twitter user accounts \\
\hline Patients with cancer/survivors & Accounts of patients with cancer receiving chemotherapy \\
$\begin{array}{l}\text { Relatives/friends of patients with cancer } \\
\text { Cancer specialists }\end{array}$ & $\begin{array}{l}\text { Accounts of a relative or a friend of a patient receiving chemotherapy } \\
\text { Accounts of people working in the oncology field }\end{array}$ \\
Health-related accounts & $\begin{array}{l}\text { Accounts of an organization in the medical field or of a person working in a medical field other than } \\
\text { oncology }\end{array}$ \\
$\begin{array}{l}\text { Media-related accounts } \\
\text { General users }\end{array}$ & \begin{tabular}{l} 
Accounts of media platforms such as newspapers and news channels \\
\hline
\end{tabular}
\end{tabular}

\section{Statistical Analysis}

Statistical analysis was performed using the SPSS software (release version 23.0.0.0, IBM Corp). Descriptive statistical analyses were used to report the frequencies for each theme and the category of the users. The chi-square test for independence was used to assess any significant associations between the types of users and the themes of the tweets. To further identify the cells that contributed to the overall significant results, adjusted residuals (z-scores) were calculated for each cell along with the $P$ values, as described by Beasley and Schumacker [18]. Taking into consideration the multiple comparisons in this analysis that might lead to type I error, a Bonferroni-adjusted $P<.001$ was utilized to indicate statistical significance.

\section{Results}

\section{Frequency of Themes and Categories of Users}

A total of 402,157 tweets were retrieved. Of these, we excluded 309,602 retweets and 62,651 irrelevant tweets (Figure 1). Therefore, 29,904 tweets were included in the final analysis. Table 3 provides the frequencies of all the themes and the user categories. Under the 9 previously identified themes, over two-thirds of the tweets $(20,288 / 29,904 ; 67.8 \%)$ expressed "prayers and wishes" for the recovery of patients with cancer on chemotherapy. Approximately 7.0\% (2084/29,904) of the tweets contained misconceptions regarding various aspects of chemotherapy. Providing "advice and information" was the third most frequent theme $(1888 / 29,904,6.3 \%)$, followed by 
tweets expressing “experience" (1847/29,904, 6.2\%) with chemotherapy for cancer management and, lastly, tweets that

used 1 or more of the keywords for "analogy" $(1556 / 29,904$, $5.2 \%)$.

Figure 1. Overview of the process of collecting and filtering the data.

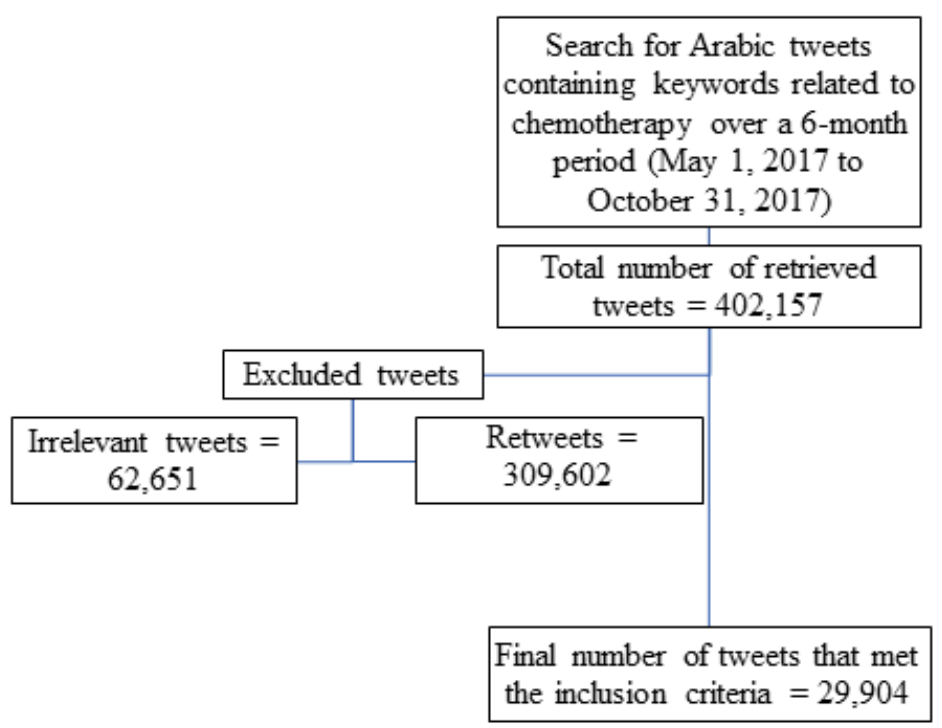

Table 3. Frequency analysis of the themes of the tweets on chemotherapy and the Twitter user categories $(\mathrm{N}=29,904)$.

\begin{tabular}{ll}
\hline Variable & $\mathrm{n}(\%)$ \\
\hline Themes & $932(3.1)$ \\
Miscellaneous & $1888(6.3)$ \\
Advice and information & $1847(6.2)$ \\
Experience & $2084(7.0)$ \\
Misconception & $20,288(67.8)$ \\
Prayers and wishes & $487(1.6)$ \\
Seeking medical information/advice & $754(2.5)$ \\
Seeking medical/financial help & $66(0.2)$ \\
Offering medical/financial help & $1556(5.2)$ \\
Analogy & \\
Category of users & $25,774(86.2)$ \\
General users & $854(2.9)$ \\
Patients with cancer/survivors & $1913(6.4)$ \\
Relatives/friends of patients with cancer & $222(0.7)$ \\
Cancer specialists & $459(1.5)$ \\
Health-related accounts & $680(2.3)$ \\
Media-related accounts &
\end{tabular}

In terms of the proportions of the categories of the users, general users represented the majority of the users in the analyzed data set $(25,774 / 29,904,86.2 \%)$. The relatives and friends of patients with cancer were the second most common contributors (1913/29,904, 6.4\%), followed by patients with cancer and survivors $(854 / 29,904,2.9 \%)$. Cancer specialists, health-related accounts, and media-related accounts represented the remaining less than $5 \%(1361 / 29,904,4.5 \%)$ of the tweets. Tweets under the theme "misconceptions" were further analyzed to capture the most common misconceptions, as described in detail in Table 4. Falsified and unrealistic side effects of chemotherapy were the most common misconceptions $(1271 / 2084,60.9 \%)$ in the studied data set. The other misconceptions were that chemotherapy causes cancer to spread $(282 / 2084,13.5 \%)$ and that chemotherapy has no therapeutic benefit $(214 / 2084,10.3 \%)$.

We compared the volumes of the tweets of misconception with the volumes of the tweets by cancer specialists and health-related accounts for the same period, and we found that the 2 noticeable 
spikes on June 1-16, 2017 and July 1-16, 2017 in the volume categories of users to tweet more (Table 5). of the tweets containing misconceptions seemed to drive both

Table 4. Frequency of the main misconceptions about chemotherapy in the Arabic tweets ( $n=2084)$.

\begin{tabular}{|c|c|}
\hline Misconceptions & $\mathrm{n}(\%)$ \\
\hline $\begin{array}{l}\text { Falsified and unrealistic side effects about chemotherapy; the main shared tweet was that "a drop of chemotherapy } \\
\text { spilled on a healthy man's skin would severely burn the skin." }\end{array}$ & $1271(60.9)$ \\
\hline Chemotherapy causes cancer to spread. & $282(13.5)$ \\
\hline Chemotherapy has no therapeutic effect on cancers. & $214(10.3)$ \\
\hline $\begin{array}{l}\text { Claims that there are natural products/preparations (eg, olive oil, Nigella sativa, ginger, almonds, camel milk or urine) } \\
\text { or other practices (eg, blood cupping, carbohydrate restriction), which are more effective than chemotherapy for treating } \\
\text { cancers }\end{array}$ & $170(8.2)$ \\
\hline Chemotherapy is prescribed so that pharmaceutical companies and physicians can make huge profits. & $67(3.2)$ \\
\hline $\begin{array}{l}\text { Claims about some pharmaceutical products (eg, vitamin B17, antibiotics, vitamin C) being more effective than } \\
\text { chemotherapy for treating cancers }\end{array}$ & $47(2.3)$ \\
\hline $\begin{array}{l}\text { Claims that there are few religious practices (eg, Roqya, Zamzam water intake, seclusion in mosque, fasting from dawn } \\
\text { to sunset), which are more effective than chemotherapy for treating cancers }\end{array}$ & $33(1.6)$ \\
\hline
\end{tabular}

Table 5. Comparison of the number of tweets containing misconceptions by any user category and the number of tweets by cancer specialists and health-related accounts during the study period.

\begin{tabular}{lll}
\hline Time period (2017) & Tweets containing misconceptions $(\mathrm{n})$ & $\begin{array}{l}\text { Tweets by cancer specialists and health-related accounts } \\
(\mathrm{n})\end{array}$ \\
\hline May 1-16 & 1616 & 35 \\
May 17-31 & 1992 & 33 \\
June 1-16 & 4365 & 108 \\
June $17-30$ & 2561 & 41 \\
July 1-16 & 3441 & 104 \\
July 17-31 & 2854 & 84 \\
August 1-16 & 2486 & 21 \\
August 17-31 & 2758 & 59 \\
September 1-16 & 2026 & 49 \\
September 17-30 & 2670 & 51 \\
October 1-16 & 1372 & 52 \\
October 17-31 & 1761 & 44 \\
\hline
\end{tabular}

${ }^{\mathrm{a}}$ Noticeable spikes in the number of tweets containing misconceptions and tweets by cancer specialists and health-related accounts.

\section{Comparison of the Themes by the Categories of the Users}

The initial Pearson chi-square test of independence showed a highly significant association between the category of the users and the themes of tweets $\left(\chi_{40}^{2}=16904.4, P<.001\right)$. Further post-hoc analyses revealed the cells that contributed the overall significance (Table 6).

Table 6 shows that general users were more likely to support patients with cancer by tweeting prayers and wishes and less likely to tweet about experiences, seeking medical intervention, and advice and information themes. Patients with cancer and the relatives and friends of patients with cancer tweeted significantly more about experiences and seeking medical advice and intervention than all other themes. They were less likely to tweet misconceptions. Cancer specialists were more likely to tweet advice and information about chemotherapy and less likely to tweet either prayers and wishes or misconceptions. Health-related accounts showed a similar statistically significant tendency as the cancer specialists to tweet more about advice and information, but they had a greater tendency to tweet about offering medical interventions. Finally, media-related accounts were more likely to tweet about advice and information but also more likely to share misconceptions than all others. In contrast, they were less likely to share tweets on prayers and wishes or tweets containing analogy. 
Table 6. Distribution of the themes by the source category.

\begin{tabular}{|c|c|c|c|c|c|c|c|c|c|}
\hline \multirow{2}{*}{$\begin{array}{l}\text { Total number of } \\
\text { tweets in each user } \\
\text { category (n) }\end{array}$} & \multicolumn{9}{|c|}{ Theme-wise tweets } \\
\hline & $\begin{array}{l}\text { Miscella- } \\
\text { neous, } \mathrm{n} \\
(\%)\end{array}$ & $\begin{array}{l}\text { Advice and } \\
\text { informa- } \\
\text { tion } \\
\mathrm{n}(\%)\end{array}$ & $\begin{array}{l}\text { Experience } \\
\mathrm{n}(\%)\end{array}$ & $\begin{array}{l}\text { Misconcep- } \\
\text { tion } \\
\mathrm{n}(\%)\end{array}$ & $\begin{array}{l}\text { Prayers } \\
\text { and wishes } \\
\mathrm{n}(\%)\end{array}$ & $\begin{array}{l}\text { Seeking } \\
\text { medical ad- } \\
\text { vice } \\
\mathrm{n}(\%)\end{array}$ & $\begin{array}{l}\text { Seeking } \\
\text { medical/fi- } \\
\text { nancial help } \\
\text { n }(\%)\end{array}$ & $\begin{array}{l}\text { Offering } \\
\text { medical/fi- } \\
\text { nancial help } \\
\mathrm{n}(\%)\end{array}$ & $\begin{array}{l}\text { Analogy } \\
\text { n (\%) }\end{array}$ \\
\hline $\begin{array}{l}\text { General users, } \\
n=25,774\end{array}$ & $760(2.9)^{\mathrm{a}}$ & $1120(4.3)^{\mathrm{a}}$ & $613(2.4)^{\mathrm{a}}$ & $1864(7.2)^{\mathrm{a}}$ & $\begin{array}{l}19,294 \\
(74.9)^{\mathrm{a}}\end{array}$ & $260(1.0)^{\mathrm{a}}$ & $291(1.1)^{\mathrm{a}}$ & $35(0.1)^{\mathrm{a}}$ & $1537(5.9)^{\mathrm{a}}$ \\
\hline $\begin{array}{l}\text { Patients with can- } \\
\text { cer/survivors, } n=854\end{array}$ & $26(3.0)$ & $24(2.8)^{\mathrm{a}}$ & $464(54.3)^{\mathrm{a}}$ & $7(0.8)^{\mathrm{a}}$ & $64(7.5)^{\mathrm{a}}$ & $3(8.5)^{\mathrm{a}}$ & $183(21.4)^{\mathrm{a}}$ & $9(1.1)^{\mathrm{a}}$ & $4(0.5)^{\mathrm{a}}$ \\
\hline $\begin{array}{l}\text { Relatives/friends of } \\
\text { patients with cancer, } \\
n=1913\end{array}$ & $34(1.8)^{\mathrm{a}}$ & $42(2.2)^{\mathrm{a}}$ & $615(32.1)^{\mathrm{a}}$ & $16(0.8)^{\mathrm{a}}$ & $821(42.9)^{\mathrm{a}}$ & $137(7.2)^{\mathrm{a}}$ & $245(12.8)^{\mathrm{a}}$ & $0(0)$ & $3(0.2)^{\mathrm{a}}$ \\
\hline $\begin{array}{l}\text { Cancer specialists, } \\
\mathrm{n}=222\end{array}$ & $4(1.8)$ & $206(92.8)^{\mathrm{a}}$ & $5(2.2)$ & $0(0)$ & $0(0)$ & $4(1.8)$ & $2(0.9)$ & $1(0.4)$ & $0(0)$ \\
\hline $\begin{array}{l}\text { Health-related ac- } \\
\text { counts, } n=459\end{array}$ & $46(10.0)^{\mathrm{a}}$ & $215(46.8)^{\mathrm{a}}$ & $46(10.0)^{\mathrm{a}}$ & $21(4.6)$ & $85(18.5)^{\mathrm{a}}$ & $13(2.8)$ & $20(4.4)$ & $7(1.5)^{\mathrm{a}}$ & $6(1.3)^{\mathrm{a}}$ \\
\hline $\begin{array}{l}\text { Media-related ac- } \\
\text { counts, } n=680\end{array}$ & $62(9.1)^{\mathrm{a}}$ & $281(41.3)^{\mathrm{a}}$ & $104(15.3)^{\mathrm{a}}$ & $176(25.9)^{\mathrm{a}}$ & $24(3.5)^{\mathrm{a}}$ & $0(0)$ & $13(1.9)$ & $14(2.1)^{\mathrm{a}}$ & $6(0.9)^{\mathrm{a}}$ \\
\hline
\end{tabular}

${ }^{\text {a }}$ Statistically significant at Bonferroni-adjusted $P<.001$.

\section{Discussion}

The aim of this study was to assess the types of conversations and misconceptions regarding chemotherapy among Twitter users in Arabic-speaking populations. Given the large number of tweets retrieved, with their further spread via retweets, our study solidified the conclusions of previous studies that showed Twitter as a rich social media platform for obtaining health-related information [19-23]. Therefore, understanding these social media websites and having a glimpse of what is shared on these websites might serve as an important step for physicians to improve the health care delivered to their patients.

Twitter also represents a growing venue for researchers to analyze on what is shared about various topics of interest in health care either related to oncology [13-19] or related to topics on other health care fields (eg, antibiotics [24], vaccinations [25], smoking [26,27]). Twitter provides researchers and health care organizations with an opportunity to outreach a wide group of participants, overcome barriers pertaining to research resources, and track emerging health-related discussions and problems in real time [28,29].

In our manual content analysis, the most common theme of the tweets was "prayers and wishes." This finding highlights a possible role of social media platforms as a support mechanism for patients with cancer receiving chemotherapy. Previous studies have also shown that social media platforms play a positive role in optimizing health care interventions [30], particularly in oncology settings [31].

Tweets containing misconceptions accounted for $7.0 \%$ $(2084 / 29,904)$ of the total tweets in our sample population, making it the second most common theme. A further analysis of the misconceptions showed that most of these misconceptions were on the unrealistic side effects of chemotherapeutic agents, and people who do not have the knowledge or the experience of chemotherapy may tend to exaggerate their harmful effects, as reported in a previous study [5]. Therefore, health care organizations and professionals must tailor their awareness activities to target such common misconceptions in a given population.

Most of the tweets on media-related accounts delivered misconceptions about chemotherapy. We also found that when there was a spike in the misconceptions during the study period, the contributions of the cancer specialists and health-related accounts also increased proportionately to correct these misconceptions and to answer the questions of other users. This proportionate increase can limit the dissemination of misconceptions because cancer specialists and health-related accounts check the medical information that is tweeted and provide reliable information through tweets prior to sharing with the followers on Twitter. Further, heath care organizations can promote the true information shared by cancer specialists and health-related accounts by using the payable option offered by Twitter to show a certain tweet in search results and user feeds so that wide groups of the targeted population can be reached with reliable information [32].

Among the themes of the studied tweets, those containing prayers and wishes were the most common. This finding corroborates that reported in previous studies that showed that religious coping strategies were the most commonly followed strategies by patients with cancer [33]. A study on Arab women in Israel who had breast cancer showed that most of them used religious coping skills to actively cope with their disease [34].

This study had the following limitations. First, even though we searched for tweets containing representative spelling variations and abbreviations for the word "chemotherapy" in Arabic, there is still a possibility of some tweets being missed. For example, some tweets may have not mentioned chemotherapy directly but may have tweeted about it indirectly. Second, even with the 
large number of tweets retrieved and analyzed, the representativeness of the users and their age groups to the whole Arabic-speaking populations cannot be guaranteed. Third, the period of the study was 6 months. Longer study periods (eg, 1 year) will possibly give a broader view and include seasonal spikes such as special occasions such as Ramadan wherein prayers and wishes for recovery can increase, which might add valuable information to the current findings. Fourth, lacking automated content analysis might limit the reproducibility of the findings to some extent. Fifth, the generalizability of the findings is limited as tweets were subjected to multiple external factors that could not be controlled such as the timing of the tweets and the geographical place wherein the users lived [35]. Lastly, some users may have appeared multiple times within the data set which, to some extent, limits the interpretation of the statistical analysis, as their views on the matter being discussed might be overrepresented. Future studies should account for bots and assess for their contributions in conversations about chemotherapy on Twitter.

In conclusion, our findings corroborate those of the previous studies that showed Twitter as a valuable social media platform to assess public perception and misconceptions about various health-related topics. Most of the tweets in our sample population showed supportive messages for patients undergoing chemotherapy, thereby suggesting that Twitter could play a supportive role for such patients, while the second most prevalent theme of the tweets in our study was misconceptions about chemotherapy. The findings of our exploratory analysis can help physicians and health care organizations tailor educational efforts in the future to address the common areas of misconceptions about chemotherapy, thereby leading to increased public acceptance of chemotherapy as a suitable mode of treatment for cancer.

\section{Conflicts of Interest}

None declared.

\section{Multimedia Appendix 1}

Arabic keywords used for searching tweets related to chemotherapy. All the keywords are the different possible spellings/abbreviations of the word "chemotherapy".

[DOCX File, 19 KB-Multimedia Appendix 1]

\section{References}

1. Chabner BA, Roberts TG. Timeline: Chemotherapy and the war on cancer. Nat Rev Cancer 2005 Jan;5(1):65-72. [doi: 10.1038/nrc1529] [Medline: 15630416$]$

2. Williams GH, Stoeber K. The cell cycle and cancer. J Pathol 2012 Jan;226(2):352-364. [doi: 10.1002/path.3022] [Medline: 21990031]

3. Chemotherapy to Treat Cancer. National Cancer Institute. 2017. URL: https://www.cancer.gov/about-cancer/treatment/ types/chemotherapy [accessed 2017-05-17]

4. Puts MTE, Tu HA, Tourangeau A, Howell D, Fitch M, Springall E, et al. Factors influencing adherence to cancer treatment in older adults with cancer: a systematic review. Ann Oncol 2014 Mar;25(3):564-577 [FREE Full text] [doi: 10.1093/annonc/mdt433] [Medline: 24285020]

5. Carelle N, Piotto E, Bellanger A, Germanaud J, Thuillier A, Khayat D. Changing patient perceptions of the side effects of cancer chemotherapy. Cancer 2002 Jul 01;95(1):155-163 [FREE Full text] [doi: 10.1002/cncr.10630] [Medline: 12115329]

6. Lindley C, McCune JS, Thomason TE, Lauder D, Sauls A, Adkins S, et al. Perception of chemotherapy side effects cancer versus noncancer patients. Cancer Pract 1999;7(2):59-65. [doi: 10.1046/j.1523-5394.1999.07205.x] [Medline: 10352062]

7. Gumusay O, Cetin B, Benekli M, Gurcan G, Ilhan MN, Bostankolu B, et al. Factors Influencing Chemotherapy Goal Perception in Newly Diagnosed Cancer Patients. J Cancer Educ 2016 Jun;31(2):308-313. [doi: 10.1007/s13187-015-0827-y] [Medline: 25851203]

8. McIlfatrick S, Sullivan K, McKenna H, Parahoo K. Patients' experiences of having chemotherapy in a day hospital setting. J Adv Nurs 2007 Aug;59(3):264-273. [doi: 10.1111/j.1365-2648.2007.04324.x] [Medline: 17590208 ]

9. What happens in an internet second: 54,907 Google searches, 7,252 tweets, 125,406 YouTube video views and 2,501,018 emails sent. DailyMail.com. 2017. URL: http://www.dailymail.co.uk/sciencetech/article-3662925/

What-happens-internet-second-54-907-Google-searches-7-252-tweets-125-406-YouTube-video-views-2-501-018-emails-sent. $\underline{\text { html }}$ [accessed 2017-05-10]

10. About Twitter. URL: https://about.twitter.com/company [accessed 2017-05-17]

11. Salem F. Social Media and the Internet of Things: Towards Data-Driven Policymaking in the Arab World-Potential, Limits and Concerns. The Arab Social Media Report series. Dubai: Mohammed Bin Rashid School of Government; 2017. URL: https://www.academia.edu/31250728/

Social Media and the Internet of Things Towards Data-Driven Policymaking in the Arab World - Potential Limits and Concerns [accessed 2019-09-08]

12. Attai DJ, Cowher MS, Al-Hamadani M, Schoger JM, Staley AC, Landercasper J. Twitter Social Media is an Effective Tool for Breast Cancer Patient Education and Support: Patient-Reported Outcomes by Survey. J Med Internet Res 2015;17(7):e188 [FREE Full text] [doi: 10.2196/jmir.4721] [Medline: 26228234] 
13. Xu S, Markson C, Costello KL, Xing CY, Demissie K, Llanos AA. Leveraging Social Media to Promote Public Health Knowledge: Example of Cancer Awareness via Twitter. JMIR Public Health Surveill 2016;2(1):e17 [FREE Full text] [doi: 10.2196/publichealth.5205] [Medline: 27227152]

14. Lenoir P, Moulahi B, Azé J, Bringay S, Mercier G, Carbonnel F. Raising Awareness About Cervical Cancer Using Twitter: Content Analysis of the 2015 \#SmearForSmear Campaign. J Med Internet Res 2017 Dec 16;19(10):e344 [FREE Full text] [doi: 10.2196/jmir.8421] [Medline: 29038096]

15. Gore RJ, Diallo S, Padilla J. You Are What You Tweet: Connecting the Geographic Variation in America's Obesity Rate to Twitter Content. PLoS One 2015;10(9):e0133505 [FREE Full text] [doi: 10.1371/journal.pone.0133505] [Medline: 26332588]

16. Tsuya A, Sugawara Y, Tanaka A, Narimatsu H. Do cancer patients tweet? Examining the twitter use of cancer patients in Japan. J Med Internet Res 2014;16(5):e137 [FREE Full text] [doi: 10.2196/jmir.3298] [Medline: 24867458]

17. G Suite Marketplace. Twitter Archiver: Google Sheets add-on. URL: https://chrome.google.com/webstore/detail/ twitter-archiver/pkanpfekacaojdncfgbjadedbggbbphi?hl=en [accessed 2017-05-11]

18. Beasley TM, Schumacker RE. Multiple Regression Approach to Analyzing Contingency Tables: Post Hoc and Planned Comparison Procedures. J Exp Educ 1995 Oct;64(1):79-93. [doi: 10.1080/00220973.1995.9943797]

19. Pemmaraju N, Utengen A, Gupta V, Kiladjian J, Mesa R, Thompson MA. Rare Cancers and Social Media: Analysis of Twitter Metrics in the First 2 Years of a Rare-Disease Community for Myeloproliferative Neoplasms on Social Media-\#MPNSM. Curr Hematol Malig Rep 2017 Dec;12(6):598-604. [doi: 10.1007/s11899-017-0421-y] [Medline: 29105027]

20. Teoh D, Shaikh R, Vogel RI, Zoellner T, Carson L, Kulasingam S, et al. A Cross-Sectional Review of Cervical Cancer Messages on Twitter During Cervical Cancer Awareness Month. J Low Genit Tract Dis 2018 Jan;22(1):8-12 [FREE Full text] [doi: 10.1097/LGT.0000000000000363] [Medline: 29271850]

21. Crannell WC, Clark E, Jones C, James TA, Moore J. A pattern-matched Twitter analysis of US cancer-patient sentiments. J Surg Res 2016 Dec;206(2):536-542. [doi: 10.1016/j.jss.2016.06.050] [Medline: 27523257]

22. Sutton J, Vos SC, Olson MK, Woods C, Cohen E, Gibson CB, et al. Lung Cancer Messages on Twitter: Content Analysis and Evaluation. J Am Coll Radiol 2018 Jan;15(1 Pt B):210-217. [doi: 10.1016/j.jacr.2017.09.043] [Medline: 29154103]

23. Diddi P, Lundy LK. Organizational Twitter Use: Content Analysis of Tweets during Breast Cancer Awareness Month. J Health Commun 2017 Mar;22(3):243-253. [doi: 10.1080/10810730.2016.1266716] [Medline: 28248621]

24. Scanfeld D, Scanfeld V, Larson EL. Dissemination of health information through social networks: twitter and antibiotics. Am J Infect Control 2010 Apr;38(3):182-188 [FREE Full text] [doi: 10.1016/j.ajic.2009.11.004] [Medline: 20347636]

25. Keim-Malpass J, Mitchell EM, Sun E, Kennedy C. Using Twitter to Understand Public Perceptions Regarding the \#HPV Vaccine: Opportunities for Public Health Nurses to Engage in Social Marketing. Public Health Nurs 2017 Jul;34(4):316-323. [doi: 10.1111/phn.12318] [Medline: 28261846]

26. Myslín M, Zhu S, Chapman W, Conway M. Using twitter to examine smoking behavior and perceptions of emerging tobacco products. J Med Internet Res 2013 Aug 29;15(8):e174 [FREE Full text] [doi: 10.2196/jmir.2534] [Medline: 23989137]

27. Rocheleau M, Sadasivam RS, Baquis K, Stahl H, Kinney RL, Pagoto SL, et al. An observational study of social and emotional support in smoking cessation Twitter accounts: content analysis of tweets. J Med Internet Res 2015 Jan 14;17(1):e18 [FREE Full text] [doi: 10.2196/jmir.3768] [Medline: 25589009]

28. Tang L, Bie B, Zhi D. Tweeting about measles during stages of an outbreak: A semantic network approach to the framing of an emerging infectious disease. Am J Infect Control 2018 Dec;46(12):1375-1380 [FREE Full text] [doi: 10.1016/j.ajic.2018.05.019] [Medline: 29929837]

29. Odlum M, Yoon S. Health Information Needs and Health Seeking Behavior During the 2014-2016 Ebola Outbreak: A Twitter Content Analysis. PLoS Curr 2018 Mar 23:10 [FREE Full text] [doi: 10.1371/currents.outbreaks.fa814fb2bec36e29b718ab6af66124fa] [Medline: 29707416]

30. Mattingly TJ. Innovative patient care practices using social media. J Am Pharm Assoc (2003) 2015;55(3):288-293. [doi: 10.1331/JAPhA.2015.14171] [Medline: 25859756]

31. Attai DJ, Cowher MS, Al-Hamadani M, Schoger JM, Staley AC, Landercasper J. Twitter Social Media is an Effective Tool for Breast Cancer Patient Education and Support: Patient-Reported Outcomes by Survey. J Med Internet Res 2015 Jul 30;17(7):e188 [FREE Full text] [doi: 10.2196/jmir.4721] [Medline: 26228234]

32. What are Promoted Tweets? Twitter Business. 2018. URL: https://business.twitter.com/en/help/overview/ what-are-promoted-tweets.html [accessed 2018-07-04]

33. Cohen M. An integrated view of cultural perceptions of cancer among Arab people in Israel. Health Psychol Rev 2014;8(4):490-508. [doi: 10.1080/17437199.2013.816205] [Medline: 25211212]

34. Goldblatt H, Cohen M, Azaiza F, Manassa R. Being within or being between? The cultural context of Arab women's experience of coping with breast cancer in Israel. Psychooncology 2013 Apr;22(4):869-875. [doi: 10.1002/pon.3078] [Medline: 22473753] 
35. Padilla JJ, Kavak H, Lynch CJ, Gore RJ, Diallo SY. Temporal and spatiotemporal investigation of tourist attraction visit sentiment on Twitter. PLoS One 2018;13(6):e0198857 [FREE Full text] [doi: 10.1371/journal.pone.0198857] [Medline: $\underline{29902270]}$

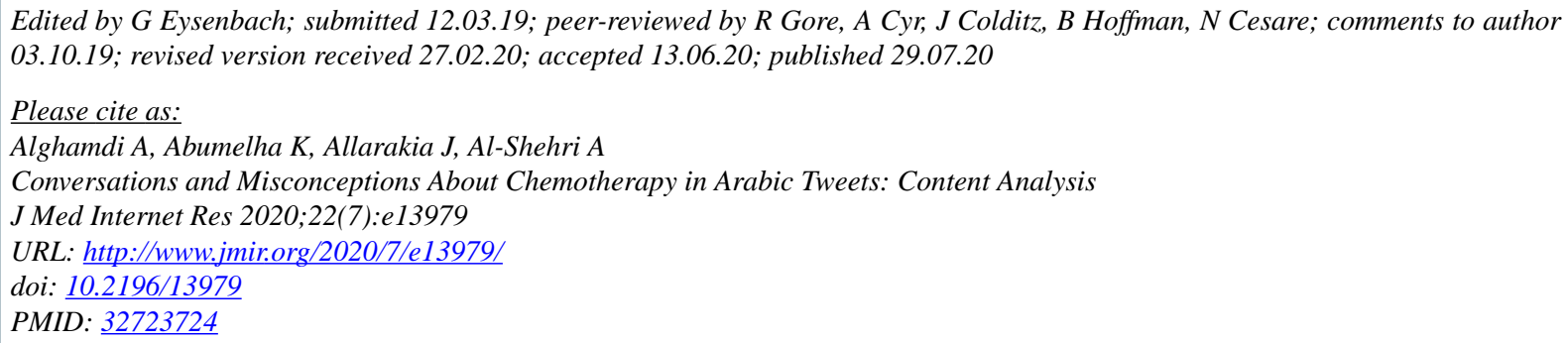

(C)Abdulrahman Alghamdi, Khalid Abumelha, Jawad Allarakia, Ahmed Al-Shehri. Originally published in the Journal of Medical Internet Research (http://www.jmir.org), 29.07.2020. This is an open-access article distributed under the terms of the Creative Commons Attribution License (https://creativecommons.org/licenses/by/4.0/), which permits unrestricted use, distribution, and reproduction in any medium, provided the original work, first published in the Journal of Medical Internet Research, is properly cited. The complete bibliographic information, a link to the original publication on http://www.jmir.org/, as well as this copyright and license information must be included. 